\title{
Role of the private sector in elective surgery in England and Wales, 1986
}

\author{
J P Nicholl, N R Beeby, B T Williams
}

\begin{abstract}
From a sample of 19000 treatment episodes at 183 of the 193 independent hospitals with operating facilities in England and Wales that were open in 1986 it is estimated that 287000 residents of England and Wales had elective surgery as inpatients in $\mathbf{1 9 8 6}$ (an increase of $77 \%$ since 1981) and 72000 as day cases. From 1985 Hospital In-Patient Enquiry data it was estimated that a further 36000 similar elective inpatient treatments were undertaken in NHS pay beds (a decrease of $38 \%$ ) and 21000 as day cases. Overall, an estimated $16.7 \%$ of all residents of England and Wales who had non-abortion elective surgery as inpatients were treated in the private sector, as were $10.5 \%$ of all day cases. An estimated $28 \%$ of all total hip joint replacements were done privately, and in both the North West and South West Thames regions the proportion of inpatients treated privately for elective surgery was $31 \%$.

It is concluded that mainly for reasons of available manpower private sector activity may not be able to grow much more without arresting or reversing the growth of the NHS, in which case some method of calculating NHS resource allocation which takes account of the local strength of the private sector will be needed.
\end{abstract}

\section{Introduction}

Many suggestions have been made recently regarding alternative methods of funding the National Health Service in the United Kingdom in order to close the reported gap between the current level of spending on the NHS and the spending required to meet the demands made upon it. ' The government is also undertaking a review of the NHS. To a greater or lesser extent most of these proposals include an expansion of the role of the private sector and some integration of it with the NHS. In this context the private sector is usually taken to mean that part of private medicine that is provided by short stay independent hospitals and by pay beds in NHS hospitals. A companion paper (p 239) reports changes in independent hospital provision and activity between 1981 and $1986,{ }^{2}$ whereas this paper examines the role of the private sector as a whole.

In an earlier study ${ }^{3}$ we examined the nature of the contribution of the private sector in 1981 to elective surgery in England and Wales and found that far from being negligible, as had been claimed by the 1979 royal commission on the NHS, ${ }^{4}$ more than one in eight of all elective operations and procedures were carried out privately. For some procedures, and particularly in some regional health authorities, more than a fifth of inpatient procedures were paid for privately outside the NHS. Even though the current review of the method of allocating NHS resources between regions makes no allowance for this considerable regional imbalance in the level of private sector activity and provision of resources, it is evident that a private sector-expanded and integrated with the NHS as is being suggested - might have to be taken into account, especially if the private sector is substituting for the NHS and not just providing additional services for patients who would not otherwise be treated.

To inform this debate and to assess the scope for using the private sector to alleviate the problems faced by the NHS we have combined the results of our study of the activity in short stay independent hospitals with information on activity in NHS pay beds and have related this to activity in the NHS public sector (hereafter referred to as the NHS).

\section{Data and methods}

The methods used to survey the activity of independent hospitals with operating theatres that were open during 1986 are described in an accompanying article (p 239). After weighting the resulting sample of 18908 patient records from the independent hospitals it was estimated that 404000 inpatients and 99000 day cases were admitted to them in 1986. This paper is mainly concerned with the subset of 286700 inpatients who were residents of England and Wales and admitted for elective surgery other than terminations of pregnancy and also the 72070 day cases admitted for elective surgery other than terminations.

For comparison the Office of Population Censuses and Surveys supplied non-maternity Hospital InPatient Enquiry data for 1985, which is the most recent year for which data are available. Hospital In-Patient Enquiry is a nominal $10 \%$ sample of all inpatient and day case discharges and deaths from NHS nonpsychiatric hospitals in England. The Welsh Office supplied Hospital Activity Analysis data for Wales for 1985, which is similar to Hospital In-Patient Enquiry data except that it is a $100 \%$ sample.

As in the earlier study we compared data from the 1986 independent hospital inpatient records with data from the most recently available, 1985, Hospital InPatient Enquiry non-maternity records for discharges and deaths of inpatients booked and on waiting lists for elective surgery, excluding abortions (which constitute $19 \%$ of the total independent hospital caseload) and residents outside England and Wales. The Office of Population Censuses and Surveys, however, would not supply information on the regional health authority of treatment or residence of day cases in the Hospital InPatient Enquiry and consequently residents from outside England and Wales have not been excluded from the day case figures (though the numbers are believed to be small).

The few amenity bed cases in the Hospital In-Patient Enquiry and Hospital Activity Analysis have been added to the NHS file. A sample of fee paying patients in NHS pay beds is also reported to the Hospital InPatient Enquiry, from which estimates of actual numbers have been made by using appropriate regional multiplying factors. These NHS pay bed patients are considered separately or in conjunction with the independent hospital patients with whom they form the private acute sector.

The weighting and rounding of estimates mean that the totals in the tables do not always equal the sum of the elements. 


\section{Results}

The regional imbalance in the distribution of private short stay beds remains. At the end of 1981 there were eight times as many private beds per head in the Thames regions as in the Northern region, and by 1986 this had fallen only slightly to a sixfold difference (see table I). Overall, in England and Wales in 1986 there was one private sector short stay bed for every 11 NHS acute specialty beds, but the ratio was one to six in the Thames regions.

As detailed elsewhere (p 239) in 1981 there were 153 independent hospitals with operating theatre facilities in England and Wales with 6592 private beds not contracted to the NHS. By 1986 the number had grown to 9466 in 193 hospitals. Over the same period the net change in the number of pay beds in NHS hospitals in England and Wales was small, increasing from 2722 in 1981 to 3036 in 1986, while the average daily number of NHS beds available in acute specialties fell from 153450 to 140982 . Despite this fall there were more admissions to these NHS beds in 1986 than in $1981,5.2$ million compared with 4.8 million, and comparing the two years the numbers of patients waiting for admission in those specialties were also larger: 714000 compared with 649000 (Department of Health and Social Security and Welsh Office, personal communication).

In 1981 excluding abortions an estimated 162000 residents of England and Wales had elective surgery as inpatients in independent hospitals, and a further 57000 were treated in NHS pay beds. By 1986 the number of inpatients in independent hospitals had grown by $77 \%$ to 287000 but the number in NHS pay beds had contracted to 36000 .

TABLE I-Acute specialty beds per 100000 population in England and Wales, 1986 (excluding obstetrics and general practice matermity specialties

\begin{tabular}{|c|c|c|c|c|}
\hline Region & $\mathrm{NHS}^{\star}$ & $\begin{array}{l}\text { Independent } \\
\text { hospitals }\end{array}$ & $\begin{array}{c}\text { NHS } \\
\text { pay beds }\end{array}$ & $\begin{array}{c}\text { Private sector } \\
\text { (independent hospitals and } \\
\text { NHS pay beds) }\end{array}$ \\
\hline Northern & 308 & $4 \cdot 0$ & $3 \cdot 3$ & $7 \cdot 3$ \\
\hline Yorkshire & 299 & $12 \cdot 7$ & $5 \cdot 4$ & $18 \cdot 1$ \\
\hline Trent & 251 & $10 \cdot 9$ & $2 \cdot 9$ & $13 \cdot 8$ \\
\hline East Anglia & 262 & $16 \cdot 2$ & $5 \cdot 4$ & $21 \cdot 6$ \\
\hline North West Thames & 247 & $35 \cdot 31$ & $8 \cdot 2+1$ & $43 \cdot 5$ \\
\hline North East Thames & 312269 & $\left.45.8\right|_{25.2}$ & $10 \cdot 9+10 \cdot 1+$ & $\left.56 \cdot 7\right|_{45 \cdot 3}$ \\
\hline South East Thames & $279^{269}$ & $28 \cdot 4^{35 \cdot 2}$ & $9 \cdot 4 t^{10 \cdot 17}$ & $37 \cdot 81^{45 \cdot 3}$ \\
\hline South West Thames & 230 & $29 \cdot 9$ & $6 \cdot 1+$ & $36 \cdot 0$ \\
\hline Wessex & 252 & $20 \cdot 3$ & $4 \cdot 0$ & $24 \cdot 3$ \\
\hline Oxford & 232 & $19 \cdot 4$ & $7 \cdot 8$ & $27 \cdot 2$ \\
\hline South Western & 274 & $10 \cdot 8$ & $3 \cdot 2$ & $14 \cdot 0$ \\
\hline West Midlands & 265 & $12 \cdot 0$ & $5 \cdot 2$ & $17 \cdot 2$ \\
\hline Mersey & 290 & $13 \cdot 3$ & $5 \cdot 3$ & $18 \cdot 6$ \\
\hline North Western & 306 & $14 \cdot 1$ & 5.9 & $20 \cdot 0$ \\
\hline Wales & 342 & $9 \cdot 7$ & $2 \cdot 0$ & 11.7 \\
\hline England and Wales & 277 & $18 \cdot 9$ & $6 \cdot 1$ & $25 \cdot 0$ \\
\hline \multicolumn{5}{|l|}{ England and Wales excluding } \\
\hline Thames regions & 280 & $12 \cdot 7$ & $4 \cdot 5$ & $17 \cdot 2$ \\
\hline Actual No of beds in each sector & 1387280 & 9466 & 3036 & 12502 \\
\hline
\end{tabular}

*Department of Health and Social Security and Welsh Office, personal communication.

†Excludes London postgraduate teaching hospitals.

FIncludes London postgraduate teaching hospitals

Including beds in directly administered hospitals there were 140982 NHS beds.

TABLE II - Estimated proportion of inpatients ${ }^{\star}$ and dav cases $\dagger$ in each age group treated in private sector and age distribution by sector of treatment, 1986

\begin{tabular}{|c|c|c|c|c|c|c|}
\hline \multirow{3}{*}{$\begin{array}{c}\text { Age } \\
\text { (years) }\end{array}$} & \multicolumn{4}{|c|}{ Age distribution $(\%)$} & \multirow{2}{*}{\multicolumn{2}{|c|}{$\begin{array}{l}\text { Proportion ("o) treated } \\
\text { in private sector }\end{array}$}} \\
\hline & \multicolumn{2}{|c|}{ Private sector } & \multicolumn{2}{|c|}{ NHS } & & \\
\hline & Inpatients & Day cases & Inpatients & Day cases & Inpatients & Day cases \\
\hline $0-14$ & $8 \cdot 3$ & $10 \cdot 4$ & $13 \cdot 3$ & $10 \cdot 6$ & $11 \cdot 1$ & $10 \cdot 4$ \\
\hline $15-44$ & 42.5 & $46 \cdot 8$ & $37 \cdot 1$ & $43 \cdot 1$ & 18.7 & $11 \cdot 4$ \\
\hline $45-64$ & $32 \cdot 7$ & $32 \cdot 2$ & $26 \cdot 8$ & $28 \cdot 2$ & $19 \cdot 7$ & 11.8 \\
\hline $65-74$ & 9.9 & $7 \cdot 1$ & 13.4 & 11.6 & 12.9 & 6.7 \\
\hline 75 and over & $6 \cdot 6$ & $3 \cdot 4$ & $9 \cdot 3$ & 6.4 & $12 \cdot 5$ & 5.9 \\
\hline All ages & $\begin{array}{c}100 \\
(\mathbf{n}=322430)\end{array}$ & $\begin{array}{c}100 \\
(\mathrm{n}=92606)\end{array}$ & $\begin{array}{c}100 \\
(n=1603900)\end{array}$ & $\begin{array}{c}100 \\
n=785979)\end{array}$ & $16 \cdot 7$ & $10 \cdot 5$ \\
\hline
\end{tabular}

^England and Wales residents admitted for elective surgery excluding abortion.

tIncluding overseas day cases.
The other major change in these five years was that the day case component of elective surgery increased substantially in all sectors. In independent hospitals the increase in elective non-abortion day case surgery was $156 \%$, while the increase in the day case component of NHS activity was $41 \%$.

\section{AGE AND SEX OF PATIENTS}

The age distribution of patients treated in the private acute sector was different from that in the NHS (table II). With regard to inpatients, the private sector treated proportionately fewer children under $15(8 \%$ compared with $13 \%)$ and fewer people over $65(16 \%$ compared with $23 \%$ ). Although the relative proportions of day cases who were children were similar in the two sectors, fewer older day case patients were treated in the private sector. These same relations held for males and females separately (data not shown).

Overall, an estimated $16.7 \%$ of all residents of England and Wales undergoing elective surgery as inpatients were treated in the private sector, as were $10.5 \%$ of all day cases (table II). Only $11 \%$ of children under 15 and $13 \%$ of patients over 65 receiving elective surgical inpatient treatment were catered for in the private sector, but for adults aged $45-64$, in the highest earning years of their working lives, this proportion was $20 \%(21 \%$ in men and $19 \%$ in women $)$. The comparative proportions in 1981 were $10 \%$ for children, $11 \%$ for patients over 65 , and $15 \%$ for patients aged 45-64. Thus the evident expansion in the private sector since 1981 applied equally to the elderly.

\section{CASELOAD COMPARISONS}

The estimated proportion of patients treated in the private sector $(16.7 \%$ for inpatients and $10.5 \%$ for day cases) may misrepresent the impact of the private sector unless the case mix is the same in the two sectors. We therefore examined the provision made by each sector for specific operations. Eight operations which had been examined in detail in 1981 were studied again. In addition, one comparatively "high tech" procedure (coronary artery bypass grafting) and two groups of largely day case procedures (endoscopies and selected operations on skin and subcutaneous tissue) were chosen for more detailed study.

For inpatients the estimated proportion of each operation carried out in the private sector ranged from $28 \%$ of hip replacements to $14 \cdot 4 \%$ of the endoscopies (table III). The proportion of the more complex bypass operations carried out privately for residents of England and Wales lay in the middle of the range at $19 \%$, but for every one of those performed on a resident of England and Wales two more were carried out on residents of other countries.

The proportion of day case procedures carried out in the private sector was less than that of inpatient procedures in all cases (table III). For example, while $21 \%$ of the selected skin operations carried out as inpatient procedures were done in the private sector, only $12 \%$ of the day case procedures were paid for privately. The reason for this difference lay in the independent hospital sector, where for both the endoscopic and the skin procedures the proportions treated as inpatients $(51 \%$ and $49 \%$ respectively) were much greater than the proportions in the NHS $32 \%$ and $30 \%$ ) and in NHS pay beds ( $26 \%$ and $24 \%$ ). There was no evidence that the reason for this difference between the sectors lay in a difference in the mix of either the endoscopic procedures or the skin operations, nor is it likely that the generally younger independent hospital patients, who, it may be presumed, also have better home conditions on average, were more often in need of overnight treatment than their counterparts in NHS hospitals. 


\begin{tabular}{|c|c|c|c|c|c|c|c|c|}
\hline \multirow{3}{*}{$\begin{array}{l}\text { Operation } \\
\text { (Office of Population Censuses and } \\
\text { Surveys code }\end{array}$} & \multicolumn{4}{|c|}{ Private sector } & \multirow{2}{*}{\multicolumn{2}{|c|}{ NHS 1985}} & \multirow{2}{*}{\multicolumn{2}{|c|}{$\begin{array}{l}\text { Proportion (\%) treated } \\
\text { in private sector }\end{array}$}} \\
\hline & \multicolumn{2}{|c|}{ Independent hospitals 1986} & \multicolumn{2}{|c|}{ NHS pay beds 1985} & & & & \\
\hline & Inpatients & Day cases & Inpatients & Day cases & Inpatients & Day cases & Inpatients & Day cases \\
\hline Tonsillectomy and adenoidectomy 233 ) & 4601 & - & 1083 & - & 29326 & 95 & $16 \cdot 2$ & - \\
\hline Repair of inguinal hernia $(411)$ & 11550 & 408 & 1064 & 69 & 58059 & 3397 & $19 \cdot 8$ & $12 \cdot 3$ \\
\hline Haemorrhoidectomy $(493)$ & 3004 & - & 213 & - & 9398 & 151 & $25 \cdot 5$ & - \\
\hline Cholecystectomy $(522)$ & +234 & - & 501 & - & 25756 & 2 & $15 \cdot 5$ & - \\
\hline Hysterectomy $(693,696)$ & 13636 & - & 781 & 14 & 47289 & 29 & $23 \cdot 4$ & - \\
\hline Total hip replacement $(810)$ & 7066 & - & 1025 & - & 21144 & 56 & $27 \cdot 7$ & - \\
\hline Excision internal structure of knee $(820)$ & 1714 & - & 304 & 14 & 7327 & 340 & $21 \cdot 6$ & - \\
\hline $\begin{array}{l}\text { Varicose veins, ligation and stripping } \\
(893,894)\end{array}$ & 10245 & 544 & 982 & 156 & 37268 & 3564 & $23 \cdot 2$ & $16 \cdot 4$ \\
\hline $\begin{array}{l}\text { Endoscopic examinations }(294,341 \text {, } \\
\quad 431,468,587,608,964) \\
\text { Selected operations on skin and }\end{array}$ & 16708 & 16215 & 1840 & 5239 & 110002 & 237048 & $14 \cdot 4$ & $8 \cdot 3$ \\
\hline $\begin{array}{l}\text { Selected operations on skin and } \\
\text { subcutaneous tissue } 910 \text { to } 929)\end{array}$ & 12428 & 12962 & 784 & 2534 & 50206 & 115488 & $20 \cdot 8$ & $11 \cdot 8$ \\
\hline Coronary artery bypass graft ( 304$)$ & 961 & - & 202 & - & 4862 & - & $19 \cdot 3$ & - \\
\hline $\begin{array}{l}\text { All other elective surgery (excluding } \\
\text { abortions) }\end{array}$ & 200556 & 41936 & 26937 & 12514 & 1203273 & 425798 & $15 \cdot 9$ & $11 \cdot 4$ \\
\hline All clective surgery (excluding abortions) & 286704 & 72066 & 35726 & 20540 & 1603910 & 785979 & $16 \cdot 7$ & $10 \cdot 5$ \\
\hline
\end{tabular}

${ }^{\star}$ England and $W$ ales residents admitted for elective surgery excluding abortion. †Including overseas day cases.

\section{REGIONAL VARIATION}

The estimated numbers of residents of England and Wales treated privately as inpatients in each region were closely similar to the numbers of residents of each region who were treated privately anywhere (table IV). The only exceptions to this overall pattern of balance in the numbers migrating in and out of the regions for private treatment were in the Thames regions, where it was apparent that many residents of the North West and South West Thames regions were treated in the North East and South East Thames regions.

In 1981 it was estimated that in terms of the proportion of the caseload for elective surgery treated in the private sector four times as many residents of the North and South West Thames regions $(22 \%)$ were treated privately as residents of the Northern region $(5 \%)$. By 1986 this imbalance had grown to a fivefold difference, with an estimated $31 \%$ of residents of the North West and South West Thames regions receiving elective surgery as inpatients being treated privately compared with only $6 \%$ of residents of the Northern region (table IV). In both Trent and Wales the proportions were also under $10 \%$.

In terms of use of resources the contribution of the private sector was less than that suggested by the proportion of patients treated privately. Only $14 \%$ of the bed days that were estimated to have been used for inpatient elective surgery for residents of England

TABLE IV-Estimated numbers of inpatients undergoing elective surgery in private sector in 1986 by region of residence and region where treatment took place, proportion of all such patients treated privately in 1981 and 1986, and proportion of bed days used for elective surgery located in private sector

\begin{tabular}{|c|c|c|c|c|c|}
\hline \multirow[b]{2}{*}{ Region } & \multirow{2}{*}{$\begin{array}{l}\text { No of residents } \\
\text { of England and Wales } \\
\text { treated in region }\end{array}$} & \multirow{2}{*}{$\begin{array}{l}\text { No of residents } \\
\text { of region treated }\end{array}$} & \multicolumn{2}{|c|}{$\begin{array}{l}\text { Proportion (\%) of } \\
\text { patients treated in } \\
\text { private sector }\end{array}$} & \multirow{2}{*}{$\begin{array}{l}\text { Proportion (\%) of } \\
\text { bed days used } \\
\text {-located in private } \\
\text { sector (1986) }\end{array}$} \\
\hline & & & 1986 & 1981 & \\
\hline Northern & 5510 & 6990 & $6 \cdot 3$ & $5 \cdot 2$ & $5 \cdot 4$ \\
\hline Yorkshire & 17140 & 17380 & $11 \cdot 4$ & $10 \cdot 8$ & $8 \cdot 7$ \\
\hline Trent & 16200 & 17810 & $9 \cdot 8$ & $10 \cdot 2$ & $8 \cdot 1$ \\
\hline East Anglia & 15740 & 11510 & 13.9 & $12 \cdot 3$ & $13 \cdot 3$ \\
\hline North West Thames & 28600 & 35730 & $31 \cdot 2$ & $21 \cdot 8$ & $28 \cdot 4$ \\
\hline North East Thames & 47470 & 31910 & $22 \cdot 0$ & $12 \cdot 8$ & $18 \cdot 3$ \\
\hline South East Thames & 32750 & 27150 & $19 \cdot 0$ & $13 \cdot 6$ & $16 \cdot 0$ \\
\hline South West Thames & 26480 & 34830 & $30 \cdot 8$ & $21 \cdot 7$ & $25 \cdot 8$ \\
\hline London ${ }^{\star}$ & 136190 & 129620 & $25 \cdot 1$ & & $21 \cdot 5$ \\
\hline Wessex & 20720 & 22660 & $19 \cdot 0$ & $14 \cdot 6$ & $15 \cdot 9$ \\
\hline Oxford & 21550 & 22110 & 21.8 & $18 \cdot 5$ & $21 \cdot 3$ \\
\hline South Western & 17390 & 18250 & $15 \cdot 1$ & $13 \cdot 6$ & $12 \cdot 1$ \\
\hline West Midlands & 28800 & 30640 & $16 \cdot 8$ & $13 \cdot 1$ & $14 \cdot 9$ \\
\hline Mersey & 10710 & 12100 & $15 \cdot 0$ & $13 \cdot 3$ & $11 \cdot 3$ \\
\hline North Western & 25220 & 23860 & $14 \cdot 2$ & $9 \cdot 3$ & $12 \cdot 3$ \\
\hline Wales & 7290 & 9530 & $8 \cdot 7$ & $10 \cdot 3$ & $6 \cdot 6$ \\
\hline All regions & 322430 & 322430 & $16 \cdot 7$ & $13 \cdot 2$ & $14 \cdot 2$ \\
\hline
\end{tabular}

*Including the four Thames regions and the London postgraduate hospitals not included in the regions. and Wales were supplied by the private sector. For residents of the North West Thames region $(28 \%)$ and South West Thames region (26\%) the proportion of bed days used supplied by the private sector was also less than the actual proportion of patients treated but still over one quarter of the total resources used when measured in this way.

\section{DURATION OF STAY}

The difference between the proportion of bed days used supplied by the private sector and the proportion of patients treated privately may reflect shorter lengths of stay. As in $1981,{ }^{6}$ there was some evidence that median lengths of stay in independent hospitals in 1986 were slightly shorter than those in the NHS (see table V), but patients in NHS pay beds were discharged earlier for every operation studied compared with patients in either the NHS or independent hospitals. Although the patterns of lengths of stay seen in 1981 and 1986 were similar, in most cases the absolute difference in lengths of stay between the sectors was reduced as a result of lengths of stay falling more in the NHS than in NHS pay beds.

Only slight differences in duration of stay between the NHS and independent hospitals remained after adjustment for differences in the age distribution (table VI).

Since the age and sex profile of independent hospital and NHS pay bed patients is similar and the social backgrounds and home circumstances of the two groups are probably similar the discrepancy between the lengths of stay of pay bed and independent hospital patients suggests different management in the two sectors.

\section{Discussion}

Since 1979 when the royal commission reported its belief that the private sector was negligible in size it has grown considerably, and we estimate that by 1986 for residents of England and Wales it provided 7\% of all non-psychiatric and non-maternity inpatient stays (of which $15 \%$ were in NHS pay beds) and $11 \%$ of all day case episodes. These estimates agree well with the findings of the 1985 general household survey that $5 \%$ of all inpatient stays for people aged 16 and over in Great Britain were paid for privately and of these $18 \%$ were in NHS pay beds. ${ }^{\top}$ Thus overall the private acute sector, which provides little maternity, psychiatric, or general medical care and no non-elective emergency care, is still dwarfed by the NHS hospital services.

Although the private sector provided only about $7 \%$ 
of all inpatient treatments, the major part of the caseload of the private sector is elective surgery, and for this one in six of all inpatient treatments for residents of England and Wales are paid for privately outside the NHS. In the North West and South West Thames regions this proportion, which was one in five in 1981, is now one in three, belying our suggestion based on the 1981 results that there might be an upper limit of about one in five on the proportion of the

TABLE V - Estimated median duration of stay selected operations according to sector of treatment

Median duration of stay (days

Private sector

Operation (Office of Population Censuses and Surveys code Independent hospitals NHS pay beds NHS

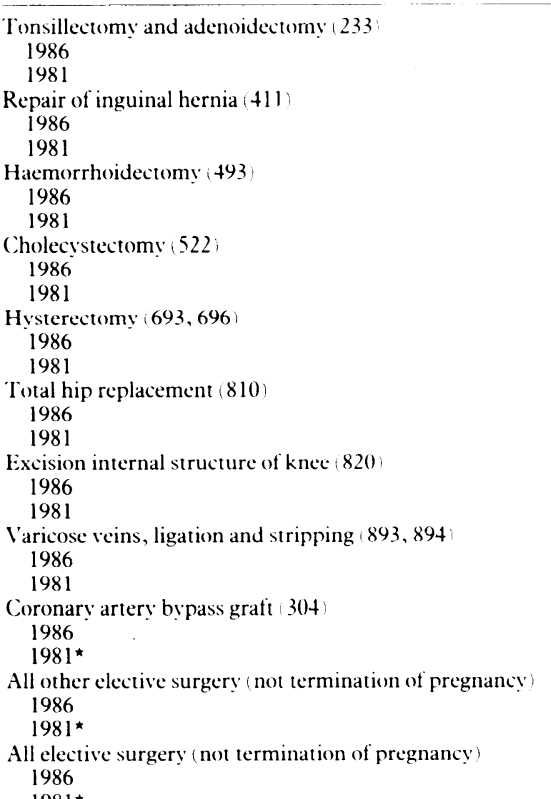

$\begin{array}{rrr}3 \cdot 0 & 2 \cdot 5 & 3 \cdot 7 \\ 3 \cdot 2 & 2 \cdot 3 & 3 \cdot 8 \\ 4 \cdot 5 & 3 \cdot 9 & 4 \cdot 4 \\ 6 \cdot 1 & 4 \cdot 2 & 5 \cdot 6 \\ 5 \cdot 8 & 5 \cdot 0 & 6 \cdot 0 \\ 7 \cdot 1 & 5 \cdot 1 & 7 \cdot 6 \\ 8 \cdot 8 & 8 \cdot 4 & 8 \cdot 9 \\ 10 \cdot 1 & 9 \cdot 8 & 10 \cdot 8 \\ 9 \cdot 8 & 8 \cdot 4 & 9 \cdot 8 \\ 11 \cdot 3 & 10 \cdot 4 & 11 \cdot 4 \\ 13 \cdot 8 & 11 \cdot 4 & 18 \cdot 4 \\ 15 \cdot 3 & 10 \cdot 8 & 19 \cdot 5 \\ 3 \cdot 4 & 3 \cdot 3 & 4 \cdot 3 \\ 5 \cdot 6 & 4 \cdot 8 & 6 \cdot 8 \\ 3 \cdot 5 & 2 \cdot 4 & 3 \cdot 4 \\ 4 \cdot 1 & 3 \cdot 4 & 4 \cdot 3 \\ 10 \cdot 8 & 10 \cdot 4 & 12 \cdot 8 \\ & & \\ 2.7 & 2 \cdot 6 & 3 \cdot 3 \\ 3.0 & & \\ & 2 \cdot 8 & 3 \cdot 6\end{array}$

*Not recorded.

TABLE VI-Estimated median duration of stay for certain operations by age and sector where treated

\begin{tabular}{|c|c|c|c|}
\hline \multirow{2}{*}{$\begin{array}{c}\text { Operation } \\
\text { (Office of Population Censuses and Surveys codes) and } \\
\text { age (years) }\end{array}$} & \multicolumn{3}{|c|}{ Sector } \\
\hline & Pay beds & Independent hospitals & NHS \\
\hline \multicolumn{4}{|l|}{ Repair of inguinal hernia 411} \\
\hline $15-44$ & $3 \cdot 0$ & $4 \cdot 1$ & $4 \cdot 1$ \\
\hline $45-64$ & $4 \cdot 1$ & $4 \cdot 6$ & $4 \cdot 6$ \\
\hline $65-74$ & 4.7 & $5 \cdot 0$ & $5 \cdot 3$ \\
\hline 75 and over & - & $5 \cdot 6$ & $6 \cdot 0$ \\
\hline \multicolumn{4}{|l|}{ Cholecystectomy (522) } \\
\hline $15-44$ & $7 \cdot 0$ & $7 \cdot 9$ & $8 \cdot 0$ \\
\hline $45-64$ & $10 \cdot 1$ & $8 \cdot 8$ & $8 \cdot 8$ \\
\hline $65-74$ & - & $11 \cdot 2$ & $10 \cdot 6$ \\
\hline 75 and over & - & - & $13 \cdot 1$ \\
\hline \multicolumn{4}{|l|}{ Hysterectomy $(693,696)$} \\
\hline $15-44$ & 8.4 & $9 \cdot 6$ & $9 \cdot 4$ \\
\hline $45-64$ & $8 \cdot 0$ & $10 \cdot 4$ & $10 \cdot 0$ \\
\hline $65-74$ & - & $9 \cdot 4$ & $10 \cdot 5$ \\
\hline 75 and over & - & - & $12 \cdot 4$ \\
\hline \multicolumn{4}{|l|}{ Total hip replacement 810} \\
\hline $15-44$ & - & - & $18 \cdot 5$ \\
\hline $45-64$ & $11 \cdot 5$ & $13 \cdot 7$ & $17 \cdot 4$ \\
\hline $65-74$ & $11 \cdot 3$ & $13 \cdot 7$ & $18 \cdot 1$ \\
\hline 75 and over & $11 \cdot 7$ & 14.8 & $20 \cdot 3$ \\
\hline \multicolumn{4}{|l|}{ Ligation and stripping of varicose veins $893 ; 894$} \\
\hline $15-44$ & $2 \cdot 4$ & $3 \cdot 3$ & $3 \cdot 1$ \\
\hline $45-64$ & $2 \cdot 5$ & 3.6 & $3 \cdot 6$ \\
\hline 65.74 & - & $3 \cdot 7$ & 3.9 \\
\hline \multirow{2}{*}{\multicolumn{4}{|c|}{ Haemorrhoidectomy (493) }} \\
\hline & & & \\
\hline $15-44$ & - & $4 \cdot 6$ & $5 \cdot 8$ \\
\hline $45-64$ & $4 \cdot 4$ & $6 \cdot 5$ & $5 \cdot 9$ \\
\hline $65-74$ & - & - & $6 \cdot 5$ \\
\hline 75 and over & - & - & $6 \cdot 4$ \\
\hline \multicolumn{4}{|l|}{ Excision internal structure of knee $(820)$} \\
\hline $15-44$ & 3.9 & $3 \cdot 7$ & $4 \cdot 4$ \\
\hline $45-64$ & - & $2 \cdot 6$ & $4 \cdot 1$ \\
\hline $65-74$ & - & - & - \\
\hline 75 and over & - & - & - \\
\hline
\end{tabular}

Bars $(-)$ indicate 10 cases or fewer. population that could afford private treatment or for whom private treatment could be afforded by their employers. The reality seems to be that , ith f lling lengths of stay and increasing real disposable incones and profits the proportion of the population willing and able to buy private treatment may be much larger.

This, however, does not mean that there are no constraints on the growth of the private sector. Elective surgery requires not only beds and facilities but doctors, nurses, ancillary staff, and managers to operate and run the hospitals. Nearly all of the medical staff currently practising in the private sector work in the NHS either as full or maximum part time consultants. The actual number of consultant surgeons (in cardiothoracic, general, paediatric, plastic, and orthopaedic surgery, neurosurgery, ophthalmology, otolaryngology, obstetrics and gynaecology, and urology) and anaesthetists working in the NHS5786 - and the number of whole time equivalents $5489^{\circ}$-indicates that on average only $5 \%$ of the standard 11 session working week is not contracted to the NHS. Our estimates show that for residents of England and Wales consultant surgeons and anaesthetists are already carrying out one private elective inpatient operation for every five NHS elective operations and one day case operation for every eight NHS operations. Even including (non-elective) emergency operations and operations for overseas residents there is one private inpatient operation for every seven NHS operations and one private day case for every nine NHS day cases. It is difficult to see how in the short term private sector activity could increase further without NHS consultants doing more work outside the normal working week, which may have consequences for the costs of treatment, or without many full time consultants switching to part time work, thereby reducing their NHS caseload. Similarly, the nursing pool is finite, and there is already evidence of shortages in nursing staff in the NHS resulting in bed closures, ${ }^{910}$ and these shortages may be exacerbated by the burgeoning private sector, which, it is known, recruits about half its nursing staff from NHS posts." This initial evidence suggests that any expansion in the private sector will, at least in the short term, result in less work being carried out in the NHS than might otherwise have been. Activity will merely be transferred from one sector to the other.

Even a simple transfer of activity from the NHS to the private sector could increase the total provision of health care in the United Kingdom if the private sector were, in some appropriate sense, more efficient than the NHS. In terms of lengths of stay, however, the data show that independent hospital patients spend about as long in hospital as the NHS hospital patients. The data presented here also show that in many cases where day case surgery is possible an unexpectedly high proportion of independent hospital patients are treated as inpatients - thereby presumably incurring the full "hotel" costs of overnight treatment. There is therefore no evidence that the major part of the private sector is more efficient than the NHS, at least in these terms.

The picture with regard to pay beds in NHS hospitals is quite different. The evidence presented here suggests that on the face of it pay beds are managed more efficiently than NHS beds. It is possible, however, that the shorter lengths of stay are achieved by pay bed patients transferring to other beds before their convalescence is over. ${ }^{6}$ The financial interests of surgeons are not affected by whether a private patient remains in a pay bed or is transferred, nor are they affected by whether a patient is treated as a day case or has an overnight stay. In both cases it is only the hotel fees that are reduced. Unit managers in NHS hospitals may, however, take a different view to 
surgeons in the future, especially if they are confronted by a need to increase their pay bed revenues.

Although the nature of the private sector has changed little between 1981 and 1986, the noticeable expansion in activity, particularly in the Thames regions, once again raises the question of the NHS procedure for resource allocation. Recently proposed revisions to this procedure would, broadly speaking, redirect funding back towards some of the Thames regions. It is difficult to see how the Thames regions can be relatively underresourced, as is implied by this redistribution, when they have the average number of acute NHS beds for the English regions and one quarter of their elective surgical treatments are provided outside the NHS. There is presumably some upper limit on the proportion of elective surgical treatments that can be provided privately before it is felt that some adjustment to the resource allocation formulas should be made. The main problem in including the private sector in the resource allocation calculations would be the practical difficulty of distinguishing between that part of the private sector activity which would otherwise have to be carried out in the NHS and activity which is merely additional to that in the NHS. This issue will become particularly important if the current government review seeks greatly to expand the role of the private sector and, in some manner, to integrate its activity with that of the NHS.

We thank the owners, directors, and staff of the independent hospitals for their collaboration; the officers of the Independent Hospitals Association; $\mathrm{Mr}$ John Randle; $\mathrm{Mr}$ Oliver Rowell of Nuffield Hospitals; Mr Barry Caulfield of British United Provident Association; and Mr David Caver of Private Patients Plan for their help.
The work was funded by the Department of Health and Social Security, which, with Trent Regional Health Authority, maintains the Medical Care Research Unit. We are grateful for their support. The views expressed in this paper, however, are those of the authors alone.

1 British Medical Association. Evidence to the government's internal review of the NHS. Br Med f 1988:296:1411-8.

Nicholl JP, Beeby NR, Williams BT. Comparison of the activity of short sta independent hospitals in England and Wales, 1981 and 1986. Br Med 1989:298:239-42

3 Nicholl JP, Thomas KJ, Williams BT, Knowelden J. Contribution of the private sector to elective surgery in England and Wales. Lancet 1984;ii: 89-92.

4 Royal Commission on the National Health Service. Report. London: HMSO, 1979:289.

5 Department of Health and Social Security. Review of the resource allocation working party. London: DHSS, 1987.

6 Williams BT, Nicholl JP, Thomas KJ, Knowelden J. Differences in length of stay for surgery in the NHS and private sector in England and Wales. Br.Med f 1985:290:978-80.

7 Office of Population Censuses and Surveys, Social Survey Division. The general household survey, 1985. London: HMSO, 1985.

8 Department of Health and Social Security. Hospital medical staff-England and Wales regional tables. 30th September 1986. London: Statistics and Research Division, DHSS, March 1987

9 Andrews J. Nursing manpower. Lancet 1987;i: 1030.

10 Working Group, Royal College of Nursing. Shortage of nurses in London. London: RCN, April 1987.

11 Thomas KJ, Nicholl JP, Williams BT. A study of the movement of nurses and nursing skills between the NHS and the private sector in England and Wales. Int F Nurs Stud 1987;25:1-10.

Accepted 28 Nonember 1988

\section{Correction}

\section{Boxing and the brain}

An editorial error occurred in this article by Professor J A N Corsellis (14 January, p 105). The painting Dempsey and Firpo, 1924 , was by the artist George Bellows and not George Bellaus as published.

\section{WORDS}

- TAlleyrand SAID it Words are the building blocks of language whereby one person conveys information to another. This is true, or should be, for scientific writing. In the wider context of language, however, this definition is naive. Talleyrand, the eighteenth century French statesman who always knew when to switch to the winning side, is credited with the remark, "Speech was given to man to disguise his thoughts." A person may imply by omission or by obliquity in his choice of words what he does not wish to say plainly. This aspect of word usage reaches its height in the diplomatic service. It also reaches a high level of sophistication in the writing of testimonials and obituaries. I shall give a few examples.

The recipient of a testimonial wants to know whether the applicant carried out his duties satisfactorily, whether he was hard working, keen, and able (and keenness and ability by no means correlate); whether he was reliable and loyal, knowledgeable and intelligent. With "open" testimonials - that is, open to the applicant and usually handed to him-adverse features of his past performance and of his character are conveyed by their omission from the foregoing list. Some knowledge of the writer may be desirable. It is said that the late Professor Gask, of the London Hospital, was in the habit of writing, "Dr Smith was my house surgeon from January to June this year." Just that; and he implied that the mere fact of the appointmen was in itself the highest recommendation. The openly hostile states that "the applicant carried out all his duties to his own satisfaction." Most of us prefer a touch of the devious, thus: "He came to us with a distinguished record from
Oxbridge"; "During the six months he had every opportunity of learning from experience." If the testimonial is an open one the writer may be able to count on an applicant's ignorance of nautical idiom, thus: "If you can find him a berth, make it a wide one." Here are some others. "He was always trying very hard-very trying." "Miss Jones was the perfect colleague to have at hand in a tight corner." Of the house physician who could never be found when wanted: "In an emergency Dr Brown would always go far beyond the call of duty." "Whoever succeeds in getting Dr Greene to work for him will indeed be fortunate."

Obituaries have much in common with testimonials. As they are "open" for relatives and friends to read they may be subject to the same obliquities of expression. Furthermore, to those who believe in a hereafter a laudatory obituary may secure entry through the pearly gates; as the following story shows (Senon E Vero, E Ben Trovato, personal communication). In the late 1940 s it was widely reported that this exchange took place:

ST PETER Who are you?

APPLICANT I am Dr Schnitzelburger.

ST PETER Not Dr Schnitzelburger, the eminent psychiatrist, by any chance?

APPLICANT (speaking with a thick Viennese accent) Well, thank you; as a matter of fact I am he.

ST PETER We're awfully glad you've come We are a bit worried about the Almighty. He thinks he's Lord Moynihan. *
De mortuis nil nisi bonum (which is generally mistranslated as "About the dead you can speak the truth"). But before I give some examples I must tell you about the two very senior registrars, one of whom said to the other, "Seen any good vacancies advertised lately?" "No," replied the other, "but there are some promising obituaries." When writing the truth about a departed colleague it may be necessary to convey the truth according to an acceptable code. Here are some examples:

"A perfectionist" means an obsessional neurotic.

"Plainspoken" means offensive.

"Not easy to know" means paranoid.

"He enjoyed life to the full" means that he was frequently drunk.

"Somewhat remote" may mean that he was almost always away.

"So popular that patients would wait six months for an outpatient appointment" means that he did his best to encourage private practice.

I make no claim to originality in the above examples of testimonials and obituaries, and if any readers believe that they have heard some of them before, I should like to quote Somerset Maugham, who said, in connection with some of his short stories, that if a story was a good one it was worth telling again.

As readers of this journal know, the editor invites self written obituaries. Mine is already in the file; it will be my final contribution.

B J FREEDMAN

^Lord Moynihan was the grand panjandrum of British surgery between the world wars. 